\title{
O. А. Янути
}

\section{КУЛЬТУРОЛОГИЧЕСКИЕ ВЗГЛЯДЫ К. Д. УШИНСКОГО}

Существующий научный дискурс не только влияет на развитие современной науки, но и задает определенную оптику восприятия наследия прошлого. Большинство фундаментальных трудов, посвященных анализу идей К. Д. Ушинского, были написаны еще в советское время. Рассматривая философские и общественно-политические взгляды великого педагога, исследователи преимущественно стремились найти в них проявление материалистических установок. В последние годы в связи с поиском новых путей развития национальной системы образования авторы все чаще обращаются к идее «народности» К.Д. Ушинского. Однако (в силу различия самих культурсловарей XIX и XXI вв.) для ее корректной интерпретации необходим комплексный анализ взглядов К.Д. Ушинского на проблемы теории и истории культуры, не проводившийся прежде. Используя теоретико-методологические подходы современной культурологии, автор данной статьи постарался частично восполнить этот пробел, представив аналитический обзор ключевых культурологических сюжетов, встречающихся в трудах К. Д. Ушинского: семантические поля использовавшихся понятий «культура», «цивилизация», «народность»; типология культур; концепция прогресса человеческой культуры, проявляющейся в постепенном переходе от синкретизма всех сфер культуры к системно-функциональной их организации; концепция нелинейного многовариантного процесса развития человечества и исторического единства происхождения разнообразных педагогических систем Европы. В рамках одной статьи невозможно представить исчерпывающий анализ всего наследия К.Д. Ушинского, однако полученные результаты позволяют расширить горизонт понимания философско-педагогических идей К.Д. Ушинского и в дальнейшем могут быть использованы при проведении исследований в области как истории педагогики, так и истории отечественной культурологии. Библиогр. 22 назв.

Ключевые слова: К.Д. Ушинский, культурология, культура, цивилизация, народность, типология культур, прогресс, нелинейное многовариантное развитие.

\section{O. A. Yanutsh}

\section{CULTUROLOGICAL VIEWS OF K. D. USHINSKIJ}

The existing scientific discourse influences not only the modern science growth vector, but a certain view on the heritage of past perception as well. Most of the fundamental works that address the ideas of K. D. Ushinskij were written in Soviet times. Scrutinizing the philosophical and socio-political views of the great teacher, researchers, mainly aimed at detecting the manifestation of materialistic ideas. Owing to the search for new ways of developing the system of national education, contemporary authors appeal to K.D. Ushinskij's concept of "nationality» ("narodnost") more and more often. However, (due to the difference between the cultural vocabularies of the nineteenth and the twentyfirst centuries), for a proper interpretation of this concept, a complex analysis of K. D. Ushinskij's views on the problems of theory and history is necessary. Such analysis has not been conducted before. By using the theoretical and methodological approaches of modern cultural studies, the paper aims at filling this lack of information by presenting an analytical overview of key culturological themes presented in the K.D. Ushinskij's works. These are the semantic fields of the concepts «culture», "civilization», "nationality», the typology of cultures, the concept of the development of culture as a gradual transition from syncretism of all spheres of culture to their system-functional organization,

Янутш Ольга Александровна - кандидат культурологии, доцент, Российский государственный педагогический университет им. А. И. Герцена, Российская Федерация, 191186, Россия, СанктПетербург, наб. p. Мойки, 48; yanutsh@gmail.com

Yanutsh Olga A. - Candidate of Science (culturology), Associate professor, Herzen State Pedagogical University of Russia, 48, Moika emb., 191186, St. Petersburg, Russian Federation; yanutsh@gmail.com

() Санкт-Петербургский государственный университет, 2017 
the concept of a non-linear, multivariate process of human development and the historical unity of the various pedagogical systems' of European origin. Although it is impossible to provide an exhaustive analysis of the entire heritage of K. D. Ushinskij in one article, still the results obtained could significantly extend the horizon of understanding K.D. Ushinskij's philosophical and pedagogical ideas and might be beneficial to further researches both in the field of the history of pedagogy and the history of Russian cultural studies. Refs 22.

Keywords: K.D. Ushinskij, culturology, cultural studies, culture, civilization, nationality, the typology of cultures, progress, nonlinear multivariate development.

Название данной статьи весьма условно. Время жизни и творчества К.Д. Ушинского приходится на тот период истории российской науки, когда понятие «культура» только начинает превращаться в значимый элемент отечественного культурсловаря, а соответствующий феномен - в предмет теоретической рефлексии [1]. Вместе с тем, как известно, на формирование научного мировоззрения К.Д. Ушинского большое влияние оказали такие предтечи философии культуры и культурологии, как Дж. Вико, И. Г. Гердер, И. Кант, Г. В. Ф. Гегель, И. Г. Фихте, Ф. В. Й. Шеллинг и др.

В работах советского периода авторы, хотя и уделяли внимание философским и общественно-политическим взглядам К.Д. Ушинского, как правило, делали это исключительно в целях оправдания его идеалистических идей (там, где опровергнуть их не представлялось никакой возможности) и выявления материалистических тенденций в развитии его мировоззрения в целом [2-4]. В последние годы было предпринято несколько попыток комплексного исследования философских взглядов великого педагога, но и в них круг вопросов, связанных с теорией и историей культуры, рассмотрен не был [5-6].

Осознавая невозможность представления исчерпывающего анализа всего наследия Ушинского в рамках одной статьи, мы хотели бы лишь обозначить несколько сюжетов, дальнейшее изучение которых, на наш взгляд, будет ценным как для истории педагогики, так и для истории отечественной культурологии.

\section{Понятия «культура» и «цивилизация» в работах К. Д. Ушинского}

Насколько нам известно, К. Д. Ушинский использовал понятие «культура» всего трижды ${ }^{1}$, и во всех случаях это было связано с работой над текстами других авторов.

Первый случай - перевод работы К. Шмидта «Письма к матери о физическом и духовном воспитании ее детей», в которой, в частности, речь идет о культуре органов питания, дыхания и кровеносной системы. Основной корпус данной «культуры» составляют следующие правила: часто чистить зубы; избегать резкого перепада температуры кушаний; носить одежду, не сдавливающую желудок; не переедать и не отвлекаться во время еды на другие занятия; заниматься дыхательной гимнастикой; содержать кожу в чистоте при помощи ванн и омовений [7, с. 119-125]. Таким образом, «культура» здесь понимается исключительно как совокупность действий по уходу, развитию, поддержанию в порядке соответствующих систем человеческого организма.

${ }^{1}$ Не считая повторов, связанных с предварительной публикацией К. Д. Ушинским материалов к «Педагогической антропологии» в виде статей. 
Следует отметить, что изначально данная работа была опубликована в «Журнале Министерства народного просвещения» в 1861 г. (№ 9-12) без указания авторства перевода. Заключение о его принадлежности К.Д.Ушинскому сделано профессором В.Я.Струминским на основе анализа ряда косвенных данных [8, c. 504-506]. Не подвергая сомнению его выводы, заметим, однако, что в своем фундаментальном труде «Человек как предмет воспитания. Педагогическая антропология» К. Д. Ушинский отзывается о работе К. Шмидта весьма категорично: «Читая эту книгу, часто кажется, что слышишь бред германской науки, где могучее слово многостороннего знания едва прорывается сквозь тучу фантазий» [9, с. 43].

Остальные два случая, имеющие для данной статьи особое значение, связаны с обращением К.Д. Ушинского к работе Ф.Э. Бенеке «Руководство к воспитанию и учению». Несмотря на то что Ушинский критиковал отдельные идеи этого немецкого философа и психолога, в целом он высоко ценил его работы, считая, что «чтения с преподавателем двух-трех таких сочинений, каковы физиологические лекции Бенеке или Гумбольдтов “Космос"», совершенно достаточно для "развития разума и расширения воззрений на жизнь» [10, с.602].

Первое обращение к понятию «культура» мы находим в главе, посвященной вопросам развития памяти, в том пассаже, где речь идет о сознании как феномене, отличающем человека от всех других живых существ. Напомним, что Ушинский выделял три элемента памяти: «элемент механический, выходящий из свойства нервной системы усваивать привычки; элемент душевный, связывающий ассоциации памяти рассудком, чувством, волей, страстью, и элемент духовный, связывающий их процессом духовного развития человека» [11, с.425]. Если первые два элемента существуют у многих животных, то последний обеспечивается уникальной способностью человеческого сознания постоянно перестраивать ряды и группы следов, «усвоенных» нервной системой, беспрестанно работать над этим материалом.

Задача воспитания, пишет Ушинский, состоит именно в том, чтобы «выплетать» в душе обширную, стройную и цельную сеть (курсив мой. - О.Я.) их комбинаций. В подтверждение своего взгляда он и приводит следующую цитату:

Вся культура и всякий успех культуры основывается на том, что каждому, уже в самом раннем детстве, сообщаются бесчисленные комбинации (ассоциации следов), не только те, которые комбинированы людьми, поставленными с воспитанником в непосредственное соотношение, но и те, которые накоплялись бесчисленными поколениями человечества в продолжение тысячелетий и всеми народами земли. Усваивая эти комбинации, человек приобретает умственное, эстетическое и моральное наследство миллионов и пользуется для своего образования плодами трудов (плодами жизни) возвышеннейших гениев, каких только производила человеческая природа $[9, \text { с. 402; 11, с. 447] }]^{2}$.

2 К.Д.Ушинский работал с немецким изданием этой работы. В переводе Н.Х. Весселя этот фрагмент звучит следующим образом: «Образование и его развитие в народе состоят именно в том, что каждому человеку с раннего детства сообщаются постоянно бесчисленные комбинации этого рода; и притом не только от лиц, непосредственно его окружающих, но и от предшествующих, иногда за тысячи лет живших поколений, от всех народов земли получает он собранные ими бесчисленные богатства. Перерабатывая эти богатства в себе, миллионы людей в свою очередь увеличивают их в умственном, эстетическом, нравственном и др. отношениях; и этот труд, включающий в себя и труд наиболее выдающихся представителей человеческого рода в духовном отношении, 
Таким образом, человек, говоря современным языком, выступает «творцом и творением культуры» в той мере, в какой его сознание способно работать с этим «материалом». Причем речь идет не только о материале собственной культуры, но и о наследии культуры мировой.

Второй случай - цитата из той же работы Бенеке, которую Ушинский, видимо, планировал использовать при определении целей и задач воспитания в III томе «Педагогической антропологии»:

Культура не есть изобретение злой воли или каприза, которую по произволу можно также отменить, но она необходимо условливается глубочайшими основами человеческой природы. Человеческая природа, в отличие от животной, содержит не только способность к культуре, но также стремление к культуре, которое с неудержимой силой гонит человека к ней, и если б можно было отказаться от культуры, то она опять была бы создана [13, с. 370].

В тексте самого Ф.Э.Бенеке данный абзац заканчивается следующим предложением: «Отрицать культуру - значит отрицать человеческую природу в ее внутренней сущности» [12, с. 7].

К вопросу о природе человека Ушинский обращался уже в своих ранних работах. В «Лекциях в Ярославском лицее», рассуждая о процессе развития человека, т. е. процессе, «которым он ближе и ближе приближается к своей человеческой сущности, к своему человеческому назначению» [14, с.161], Ушинский приходит к выводу о невозможности этого развития вне общества. В равной степени критикуя односторонние взгляды как идеалистов, так и позитивистов, он объясняет уникальность природы человека единством трех ее сторон: во-первых, «животною природою; во-вторых, инстинктом общественности - исключительною принадлежностью животного человека; и, в-третьих, необходимою потребностью совершенствования развития - потребностью духовного человека, потребностью духа» $[14$, c. 64$]$.

Эта идея - о биосоциокультурной природе человека - в дальнейшем неоднократно повторялась Ушинским в том или ином виде во многих статьях. Наиболее полно, вероятно, она должна была быть развернута в III томе «Педагогической антропологии», в котором, по мнению В. Я. Струминского, автор планировал использовать большой культурно-исторический материал для анализа социально-исторических факторов, определяющих принципиальное отличие психики человека от психики животных [2].

В отличие от «культуры», понятие «цивилизация» используется Ушинским часто (около сотни раз), причем как в переводных работах, так и в собственных. В целом здесь мы встречаем характерное для того времени понимание цивилизации как «государственного быта», невозможного в общинно-родовых сообществах и связанного с определенным типом социально-политических и общественных отношений. Нам представляется важным выделить два лейтмотива, определяющих горизонт использования данного понятия Ушинским.

принадлежит к самым плодотворным для развития человека» [12, с. 42]. Отметим здесь два момента: 1) несмотря на то что понятие «культура» Н.Х. Вессель использовал при переводе данной работы часто, здесь он предпочел понятие «образование»; 2) речь идет не только о «выдающихся гениях», но о труде, который постоянно осуществляют миллионы людей. 
С одной стороны, противопоставление «цивилизации» и «дикости» как разных уровней (ступеней) развития общества. Прогресс цивилизации - единственный и универсальный путь, по которому должен двигаться любой народ, который хочет избежать стагнации и гибели [15, с.437].

Причем речь идет не только о разных народах. Даже в разных слоях одного и того же общества уровень цивилизации может быть разным: «...в основу всяких прочных улучшений в народном быте, в основу всякого движения вперед иивилизации сельского населения (курсив мой. - О.Я.) должна, необходимо, неизбежно, лечь народная школа, которая бы ... открыла зрение и слух, душу и сердце народа урокам великих наставников человечества: природы, жизни, науки и христианской религии» $[16$, с. 254].

В этом смысле важной чертой «цивилизации» для Ушинского является не столько формальная специфика государственной, гражданской формы организации жизни общества, сколько идея человечности (в широком смысле слова), противопоставленная варварству. Поэтому, в частности, он утверждал, что «всякий новый шаг цивилизации» в Северной Америке неудержимо должен привести к искоренению рабства, основанного на «нарушении коренного закона христианства» $[17$, с. 334$]$.

Он выделяет два элемента «цивилизации», которые должны находиться в неразрывной связи: уровень жизни граждан и смысл, ценностное наполнение этой жизни. Одностороннее развитие цивилизации - зло. Научно-технический прогресс (железные дороги, промышленность, «промышленническая литература», «готовые понятия и готовые фразы, сыплющиеся в современное дитя из множества книг и множества уст, прежде чем оно само и самостоятельно успеет подумать о чем-нибудь», постоянное увеличение потребностей и наслаждений [18]) приводит к разрушению нравственности и, в конечном счете, к остановке в развитии, загниванию общества.

Однако это не означает необходимости сохранять и поддерживать патриархальную нравственность. Хотя Ушинский и признает, что в ней содержатся ценнейшие и чистейшие «глубокие следы христианства, которые, может быть, тем глубже, чем древнее», он считает, что остановка в развитии нравственности является также губительной для общества: «Человек вначале как бы раздвояется, и в сердце у него некоторое время уживаются очень мирно патриархальная нравственность в отношении своего семейства и совершенная безнравственность за границею семейства... где над ним существует только право силы, а за ним право всякого рода хитрости и обмана» [15, с. 433-438].

Поэтому для успешного развития общества, по мнению Ушинского, цивилизация, неизбежно разрушая патриархальную нравственность любого народа, должна привносить с собой новую, общечеловеческую нравственность.

С другой стороны, Ушинский неоднократно использует понятие «цивилизация» во множественном числе («цивилизации азиатских народов», «великие цивилизации Востока, Индии и Китая» [19, с.540-542]), а также для обозначения специфики «европейской цивилизации», «русской цивилизации», «цивилизации Северной Америки» и пр. При этом интерес для Ушинского представляют не только локальные изивлизации прошлого и настоящего, но и все типы исторических обществ. 


\section{Понятие «народность» и типология культур}

Ю. Асоян отмечает, что понятие «народность» - «один из важнейших моментов формирующегося в середине прошлого столетия русского культурсловаря» [1, c.91]. Для К. Д. Ушинского в трактовке этого понятия ключевую роль играло представление об уникальном «духе» каждого народа, сформировавшееся под влиянием работ В. Гумбольдта, И. Г. Гердера, Г. В. Ф. Гегеля и др.

С одной стороны, этот «дух» понимается им как уникальная и самобытная общность характера народа, зависящая от «одинаковости происхождения, от одной местности, занимаемой этим обществом, и, наконец, от одинакового исторического положения» $[14$, с.69]. Формирование «народности» связано с переходом от семейно-родовой общины к возникновению племен, где «человек связывается с другими уже не чувствами, не числом, а мыслью, единством языка, единством религии, единством той земли, на которой они живут и оразноображенное единство которой выражают в оразноображенном единстве своего характера» [20, с. 165]. В этом контексте то значение, которое Ушинский придавал изучению родного языка, было, очевидно, обусловлено в большей степени философией языка Гумбольдта, нежели эстетическими идеями славянофилов. Язык есть дух народа: не только его лексический состав, но и вся его структура неотделимы от специфики мировоззрения, системы восприятия и освоения мира, определяющей уникальный дух каждого народа.

С другой стороны, народность понимается как источник жизни общества в истории, та идея, благодаря которой разные исторические общества «являются отдельными, самостоятельными личностями (курсив мой. - О.Я.) в развитии всего человечества» $[14$, с. 66].

Со временем «обычаи множатся, дробятся, забываются, находят себе противоречие в новых образах действий, происходящих или из случайностей исторических, или от влияния новых местностей и случайных характеров на характеры членов общества»; «язык распадается на ветви, наречия и подречия; религия на различные культы, обычаи; и весь характер народный вместе с разрождением и расселением народа разнообразится, распадается». На этом этапе народ может забыть «свою» идею, свою историческую роль. И в этом случае он «должен удалиться со сцены»: «Народ без народности - тело без души, которому остается только подвергнуться закону разложения и уничтожиться в других телах, сохранивших свою самобытность» $[21$, с. 161].

Чтобы этого не произошло, недостаточно только страны и народа «со своим особенным характером». Необходимо еще и наличие «исторического разума»: концентрированного смысла, идеи $[14$, с.78]. Причем здесь речь уже не идет о некой общечеловеческой идее. У каждого народа она должна быть собственной: «История не терпит повторений и подражаний» [14, с. 117].

Критикуя как западников, так и славянофилов, К.Д. Ушинский обвиняет их в стремлении «разрушить самостоятельность русской жизни, уничтожить нас как народ, отняв у нас наш отличительныц тип (курсив мой. - О.Я.), вырвать идею из нашей жизни, разрушив великую цель в истории» [14, с.117]. По его мнению, «идея» назначения России скрывается в связи «быта патриархального с государственным, азиатского - с европейским»: «это соединение дает нам самостоятель- 
ный тип, делает самостоятельным в кругу других, а без этой самобытности нет для народа жизни в истории» $[14, \text { с. } 117]^{3}$.

На основе этого дуализма феномена народности (как объективно существующего самобытного «характера народа» и как исторической идеи, «силы развития», определяющей судьбу народа в истории) Ушинский выделяет четыре группы народностей:

1) «народности, слишком слабые для самостоятельного исторического развития и осужденные на поглощение другими народностями» («краснокожие Америки, эскимосы, негритосы и др.»);

2) «народности, еще дожидающие своей очереди, чтобы войти в область истории» (народности, достаточно сильные, «чтобы внести в историю новую деятельную личность, но которые, по той или другой географической и исторической причине, не вошли еще в область истории»);

3) народности, уже вышедшие из области истории и «догнивающие свой век» (Греция после Александра Македонского, современный Ушинскому Китай);

4) «народности современно-исторические» [15, с. 435-437].

Таким образом, мысль Ушинского развивалась в том же направлении, которое одновременно с ним привело Н. Я. Данилевского к созданию известной концепции культурно-исторических типов ${ }^{4}$ и, чуть позже, к появлению концепций О.Шпенглера и Тойнби.

\section{Идеи прогресса и вариативности в истории культуры}

Как уже было сказано выше, рассмотрение специфики культурно-исторического контекста развития человечества должно было, вероятно, составить часть содержания III тома «Педагогической антропологии». Вместе с тем и в опубликованных работах К. Д. Ушинского можно выделить несколько сюжетов, относящихся к области исторической культурологии.

Во-первых, это круг идей, связанных с развитием каждого конкретного исторического общества. Ядром здесь выступала концепция народа как «общественного организма», снова вошедшая в актуальный для того времени философскотеоретический дискурс благодаря работам И. Канта, Г. В.Ф. Гегеля, Ф. В. Шеллинга, Г. Спенсера и др.

В своем развитии общество проходит ряд ступеней: от семьи через род и племя к гражданскому обществу и государству. При этом «ступени, по которым развивается организм общества, не умирают, но входят одни в другие, так что низшие отдают высшим все, что не принадлежит им, и оставляют себе одну только сущность»

3 Отметим, что специфика этого типа - это еще не сама идея, идея лишь «скрывается» в ней. Двенадцать лет спустя в «Письмах о воспитании наследника русского престола» К. Д. Ушинский признается: «Но, может быть, вы спросите меня, что такое русские убеждения? Знаю ли я их? Где их отыскать? - На это я отвечу вам: что я их не знаю, что я их не нашел, но что они должны быть, что они чувствуются сердцем и что если их можно найти, то, конечно, уже не за границей» [10, с. 578].

4 Хотя работа Н.Я.Данилевского «Россия и Европа» была опубликована в журнале «Заря» в 1869 г., за год до смерти К. Д. Ушинского, мы не нашли информации о том, мог ли последний быть с нею знаком. Вместе с тем сам Ушинский был достаточно яркой фигурой своего времени, и Данилевский не мог не читать его статью «О народности в общественном воспитании», опубликованную в 1857 г. и одобрительно встреченную обществом. 
[20, с. 202-204]. Все высшие ступени (высшие сферы жизни общества), в свою очередь, уже содержатся в низших, «но только почти в одной возможности».

Выражаясь современным языком, принцип этого развития заключается в постепенном переходе от синкретизма всех сфер культуры (политической, экономической, религиозной и пр.) к системно-функциональной их организации. Первый тип соединения Ушинский называет «химическим», а второй - «органическим», оговариваясь, что «эти выражения заимствованы из естественных наук потому, что для выражения различных родов соединений мы других выражений не имеем» [20, c.203]. Второй круг идей связан с поиском общей логики развития человечества в целом.

Можно сказать, что Ушинский в некотором смысле разделял идею прогрессивного развития человечества. Однако этот прогресс обеспечивается не за счет стремления к некой трансцендентной идее, задающей единственно верный вектор развития, а за счет самой природы человека и вытекающих из нее объективных законов существования общества.

Духовная потребность человека в развитии, подпитываемая культурным наследием различных народов и эпох, непосредственно влияет и на развитие форм общественных организмов (поиск новых форм, адекватных новому содержанию). Именно это, по мнению Ушинского, «сделало из Европы вторую ступень в развитии человечества и дало истории Азии смысл одного великого исторического периода, выполнявшего свое назначение» [19, с. 541-542].

Ни о том, что является идеалом этого развития, ни о том, какими могут быть его следующие ступени, Ушинский не пишет. В материалах к III тому «Педагогической антропологии», ведя заочный спор с Бенеке о цели воспитания, он, отчасти цитируя, отчасти излагая своими словами, приводит следующий фрагмент из работы «Руководство к воспитанию и учению»: «“О всеобеей врожденности такого идеала при нынешнем состоянии психологии не может быть и речи”... Но если этот идеал делается, то где же ручательство, что тот, который мы составили, - настоящий?». Далее в скобках следует комментарий-восклицание самого Ушинского: «А я спрошу: есть ли настоящий?» [13, с.369].

В контексте данного раздела показательно, что фрагмент, пересказанный Ушинским своими словами, - это вторая часть предложения, начинающегося у Бенеке следующим образом: «Успехи культуры, вообще, идут отнюдь не по прямой линии к совершенству, а окольными путями и нередко даже с возвратными отступлениями...» [12, с.6].

Действительно, идеи Ушинского о судьбе разных народностей в истории свидетельствуют о том, что он был склонен представлять развитие человечества скорее как нелинейный многовариантный проиесс. Наиболее ярко эта идея просматривается, конечно, в его работе «О народности в общественном воспитании».

Как правило, исследователи-педагоги обращают особое внимание на представленные в ней выводы о принципиальном своеобразии систем народного воспитания, невозможности их заимствования одним народом у другого и пр. Часто в дополнение указывают, что при этом Ушинский осуждал желание некоторых реформаторов «поставить нашу школу непременно не так, как у людей, “до горы ногами”» и считал, что «опыт других народов в деле воспитания есть драгоценное наследие для всех» (см., напр.: [22, с. 73]). 
На наш взгляд, культурологическая ценность данной работы состоит как раз в предпринятой Ушинским попытке найти теоретическое обоснование возможности непротиворечивого единства двух позиций: концепции всечеловеческой истории, с одной стороны, и индивидуального пути развития отдельных народов с другой.

Результатом стала идея исторического единства происхождения разнообразных педагогических систем Европы. Анализируя общее и особенное в воспитательных системах разных народов Европы, Ушинский приходит к выводу, не потерявшему актуальности для культурологической мысли и сейчас: «...обращаясь к истории, мы видим, что все эти разнородные системы - ветви одного могучего растения, семя которого было посеяно общей для всех христианской церковью» [21, с. 71].

\section{Литература}

1. Асоян Ю., Малафеев А. Открытие идеи культуры (Опыт русской культурологии середины XIX - начала XX веков). М.: ОГИ, 2001. 344 с.

2. Струминский В.Я. Очерки жизни и педагогической деятельности К. Д. Ушинского. М.: Учпедгиз, 1960. 347 с.

3. Лордкипанидзе Д. О. Педагогическое учение К.Д. Ушинского. М.: Учпедгиз, 1950. 368 с.

4. Гончаров Н. К. Педагогическая система К. Д. Ушинского. М.: Педагогика, 1974. 270 с.

5. Бельский В.Ю. Философско-антропологическая теория К.Д.Ушинского. М.: Московский ун-т МВД России, 2003. 264 с. $157 \mathrm{c}$.

6. Защепин А. В. Философские идеи К. Д. Ушинского. Мичуринск: ФГБОУ ВПО «МГПИ», 2012.

7. Шмидт К. Письма к матери о физическом и духовном воспитании ее детей // Архив К. Д. Ушинского: в 4 т. / Акад. пед. наук РСФСР, Ин-т теории и истории педагогики. М.: Изд-во Акад. пед. наук РСФСР, 1961. Т.3. С. 110-248.

8. Архив К.Д. Ушинского: в 4 т. М.: Изд-во Акад. пед. наук РСФСР, 1961. Т. 3.534 с.

9. Ушинский К. Д. Человек как предмет воспитания (Опыт педагогической антропологии). Т. I // Ушинский К.Д. Собрание сочинений: в 11 т. М.; Л.: Изд-во Акад. пед. наук РСФСР, 1950. Т. 8. C. 11-679.

10. Ущинский К. Д. Письма о воспитании наследника русского престола // Архив К. Д. Ушинского: в 4 т. М.: Изд-во Акад. пед. наук РСФСР, 1962. Т. 4. С. 573-603.

11. Ушинский К. Д. Главнейшие черты человеческого организма в приложении к искусству воспитания // Архив К. Д. Ушинского: в 4 т. М.: Изд-во Акад. пед. наук РСФСР, 1961. Т.3. С. 251-491.

12. Бенеке Ф. Э. Руководство к воспитанию и учению. Ч. 1: Руководство к воспитанию. СПб.: Изд. А. Черкесова и Кํ 1875 . [8], XVI, 406 с.

13. Материалы к 3-му тому «Педагогической антропологии» // Ушинский К. Д. Собрание сочинений: в 11 т. М.; Л.: Изд-во Акад. пед. наук РСФСР, 1950. Т. 10. С. 53-622.

14. Ушинский К. Д. Лекции в Ярославском лицее (1846-1848 гг.) // Ушинский К.Д. Собрание сочинений: в 11 т. М.; Л.: Изд-во Акад. пед. наук РСФСР, 1948. Т. 1. С. 51-120.

15. Уиинский К. Д. О нравственном элементе в воспитании // Ушинский К.Д. Собрание сочинений: в 11 т. М.; Л.: Изд-во Акад. пед. наук РСФСР, 1948. Т. 2. С. 425-488.

16. Ущинский К. Д. Вопросы о народных школах // Ушинский К.Д. Собрание сочинений: в 11 т. М.; Л.: Изд-во Акад. пед. наук РСФСР, 1948. Т. 2. С. 250-262.

17. Ушинский К. Д. Труд в его психическом и воспитательном значении // Ушинский К. Д. Собрание сочинений: в 11 т. М.; Л.: Изд-во Акад. пед. наук РСФСР, 1948. Т. 2. С.333-361.

18. Ушинский К. Д. Человек как предмет воспитания (Опыт педагогической антропологии). Т. II // Ушинский К.Д. Собрание сочинений: в 11 т. М.; Л.: Изд-во Акад. пед. наук РСФСР, 1950. Т.9. C. $13-562$.

19. Ушинский К. Д. Магазин землеведения и путешествий. Географический сборник, издаваемый Николаем Фроловым, т. II // Ушинский К.Д. Собрание сочинений: в 11 т. М.; Л.: Изд-во Акад. пед. наук РСФСР, 1948. Т. 1. С. 512-554.

20. Ушинский К. Д. О камеральном образовании (Речь на торжественном собрании лицея 18/IX 1848 г.) // Ушинский К.Д. Собрание сочинений: в 11 т. М.; Л.: Изд-во Акад. пед. наук РСФСР, 1948. T.1. C. 121-249. 
21. Ущинский К.Д. О народности в общественном воспитании // Ушинский К. Д. Собрание сочинений: в 11 т. М.; Л.: Изд-во Акад. пед. наук РСФСР, 1948. Т. 2. С. 69-166.

22. Гончаров И. Ф. К.Д. Ушинский и русская национальная школа // Universum: Вестник Герценовского университета. 2009. № 3. С. 69-79.

Для цитирования: Янутш О.А. Культурологические взгляды К.Д.Ушинского // Вестник СПбГУ. Философия и конфликтология. 2017. Т.33. Вып. 3. С.343-353. DOI: 10.21638/11701/spbu17.2017.310.

\section{References}

1. Asoian Iu., Malafeev A. Otkrytie idei kul'tury (Opyt russkoi kul'turologii serediny XIX - nachala XX vekov) [Opening cultural ideas (Russian Experience in Cultural Studies mid XIX - early XX centuries)]. Moscow, OGI Publ., 2001. 344 p. (In Russian)

2. Struminskii V.Ia. Ocherki zhizni i pedagogicheskoi deiatel'nosti K.D. Ushinskogo [Essays on the life and teaching activities of K. D. Ushinskij]. Moscow, Uchpedgiz Publ., 1960. 347 p. (In Russian)

3. Lordkipanidze D. O. Pedagogicheskoe uchenie K.D. Ushinskogo [K.D. Ushinskij's teacher doctrine]. Moscow, Uchpedgiz Publ., 1950. 368 p. (In Russian)

4. Goncharov N.K. Pedagogicheskaia sistema K.D. Ushinskogo [Pedagogical system of K.D. Ushinskij]. Moscow, Pedagogika Publ., 1974. 270 p. (In Russian)

5. Bel'skii V.Iu. Filosofsko-antropologicheskaia teoriia K.D. Ushinskogo [The philosophical-anthropological theory of K. D. Ushinskij]. Moscow, Moscow Univ. of MVD Publ., 2003. 264 p. (In Russian)

6. Zatsepin A.V. Filosofskie idei K.D. Ushinskogo [Philosophical ideas of K.D. Ushinskij]. Michurinsk, FGBOU VPO “MGPI" Publ., 2012. 157 p. (In Russian)

7. Shmidt K. Pis'ma k materi o fizicheskom i dukhovnom vospitanii ee detei [Letters to mother about the physical and spiritual education of her children]. Arkhiv K.D. Ushinskogo [Archive of K.D. Ushinskij], in 4 vol. Moscow, Academy of Pedagogical Sciences of RSFSR Publ., 1961, vol.3, pp. 110-248. (In Russian)

8. Arkhiv K.D. Ushinskogo [Archive of K.D. Ushinskij], in 4 vols. Moscow, Academy of Pedagogical Sciences of RSFSR Publ., 1961, vol.3. 534 p. (In Russian)

9. Ushinskii K. D. Chelovek kak predmet vospitaniia (Opyt pedagogicheskoi antropologii) [Man as the subject of education (pedagogical anthropology experience)], vol. I. Ushinskij K. D. Sobranie sochinenii [Collected works], in 11 vols. Moscow, Leningrad, Academy of Pedagogical Sciences of RSFSR Publ., 1950, vol. 8, pp. 11-679. (In Russian)

10. Ushinskii K.D. Pis'ma o vospitanii naslednika russkogo prestola [Letters on educating the heir to the Russian throne]. Arkhiv K.D. Ushinskogo [Archive of K.D. Ushinskij], in 4 vols. Moscow, Academy of Pedagogical Sciences of RSFSR Publ., 1962, vol.4, pp. 573-603. (In Russian)

11. Ushinskii K. D. Glavneishie cherty chelovecheskogo organizma v prilozhenii k iskusstvu vospitaniia [The main features of the human body in the application to the art of education]. Arkhiv K.D. Ushinskogo [Archive of K. D. Ushinskij], in 4 vols. Moscow, Academy of Pedagogical Sciences of RSFSR Publ., 1961, vol.3, pp. 251-491. (In Russian)

12. Beneke F. E. Rukovodstvo $k$ vospitaniiu i ucheniiu. Ch. 1: Rukovodstvo $k$ vospitaniiu [Guide to the care and education. Part 1: A guide to parenting]. St. Petersburg, 1875. 406 p. (In Russian)

13. Materialy k 3-mu tomu "Pedagogicheskoi antropologii" [Materials for the 3rd volume of "Pedagogical Anthropology"]. Ushinskij K. D. Sobranie sochinenii [Collected works], in 11 vols. Moscow, Leningrad, Academy of Pedagogical Sciences of RSFSR Publ., 1950, vol. 10, pp. 53-622. (In Russian)

14. Ushinskii K. D. Lektsii v Iaroslavskom litsee (1846-1848 gg.) [Lectures in Yaroslavl Lyceum (18461848)]. Ushinskij K. D. Sobranie sochinenii [Collected works], in 11 vols. Moscow, Leningrad, Academy of Pedagogical Sciences of RSFSR Publ., 1948, vol. 1, pp. 51-120. (In Russian)

15. Ushinskii K.D. O nravstvennom elemente v vospitanii [About the moral element in education]. Ushinskij K. D. Sobranie sochinenii [Collected works], in 11 vols. Moscow, Leningrad, Academy of Pedagogical Sciences of RSFSR Publ., 1948, vol.2, pp. 425-488. (In Russian)

16. Ushinskii K.D. Voprosy o narodnykh shkolakh [Questions about public schools]. Ushinskij K.D. Sobranie sochinenii [Collected works], in 11 vols. Moscow, Leningrad, Academy of Pedagogical Sciences of RSFSR Publ., 1948, vol.2, pp. 250-262. (In Russian)

17. Ushinskii K. D. Trud v ego psikhicheskom i vospitatel'nom znachenii [Work in its mental and educational value]. Ushinskij K. D. Sobranie sochinenii [Collected works], in 11 vols. Moscow, Leningrad, Academy of Pedagogical Sciences of RSFSR Publ., 1948, vol.2, pp.333-361. (In Russian)

18. Ushinskii K. D. Chelovek kak predmet vospitaniia (Opyt pedagogicheskoi antropologii) [Man as the subject of education (pedagogical anthropology experience)], vol. II. Ushinskij K. D. Sobranie sochinenii 
[Collected works], in 11 vols. Moscow, Leningrad, Academy of Pedagogical Sciences of RSFSR Publ., 1950, pp. 13-562. (In Russian)

19. Ushinskii K.D. Magazin zemlevedeniia i puteshestvii. Geograficheskii sbornik, izdavaemyi Nikolaem Frolovym [Shop of geography and travel. Geographic collection, published by Nikolai Frolov], vol. II. Ushinskij K. D. Sobranie sochinenii [Collected works], in 11 vols. Moscow, Leningrad, Academy of Pedagogical Sciences of RSFSR Publ., 1948, vol. 1, pp.512-554. (In Russian)

20. Ushinskii K. D. O kameral'nom obrazovanii (Rech' na torzhestvennom sobranii litseia 18/IX 1848 g.) [About cameral Education (Speech at the solemn meeting of the Lyceum 18 / IX 1848)]. Ushinskij K.D. Sobranie sochinenii [Collected works], in 11 vols. Moscow, Leningrad, Academy of Pedagogical Sciences of RSFSR Publ., 1948, vol. 1, pp.121-249. (In Russian)

21. Ushinskii K.D. O narodnosti v obshchestvennom vospitanii [On the national features in public education]. Ushinskij K. D. Sobranie sochinenii [Collected works], in 11 vols. Moscow, Leningrad, Academy of Pedagogical Sciences of RSFSR Publ., 1948, vol.2, pp.69-166. (In Russian)

22. Goncharov I. F. K. D. Ushinskii i russkaia natsional'naia shkola [K. D. Ushinskij and Russian national school]. Universum: Herzen University's bulletin, 2009, no. 3, pp. 69-79. (In Russian)

For citation: Yanutsh O. A. Culturological views of K. D. Ushinskij. Vestnik SPbSU. Philosophy and Conflict studies, 2017, vol.33, issue 3, pp. 343-353. DOI: 10.21638/11701/spbu17.2017.310.

Статья поступила в редакцию 13.11.2016

Статья рекомендована в печать 16.03.2017 